\title{
Reduction in tuberculosis incidence in the UK from 2011 to 2015: a population-based study
}

\author{
H Lucy Thomas, ${ }^{1}$ Ross J Harris, ${ }^{2}$ Morris C Muzyamba, ${ }^{1}$ Jennifer A Davidson, ${ }^{1}$ \\ Maeve K Lalor, ${ }^{1}$ Colin N J Campbell, ${ }^{1,3}$ Sarah R Anderson, ${ }^{1}$ Dominik Zenner ${ }^{1,3}$
}

\begin{abstract}
- Additional material is published online only. To view please visit the journal online (http://dx.doi.org/10.1136/ thoraxjnl-2017-211074).
\end{abstract}

${ }^{1}$ Respiratory Diseases Department, National Infection Service, Public Health England, London, UK

${ }^{2}$ Statistics, Modelling and Economics Department, National Infection Service, Public Health England, London, UK ${ }^{3}$ Institute for Global Health, University College London, London, UK

\section{Correspondence to}

Dr H Lucy Thomas, Respiratory Diseases Department, National Infection Service, Public Health England, London NW9 5EQ, UK : lucy.thomas@phe.gov.uk

Received 22 September 2017 Revised 23 January 2018 Accepted 26 March 2018 Published Online First 19 April 2018

\section{SLinked}

- http://dx.doi.org/10.1136/ thoraxinl-2018-211537

Check for updates

To cite: Thomas HL, Harris RJ, Muzyamba MC, et al. Thorax

2018:73:769-775.

\section{ABSTRACT}

Background Following nearly two decades of increasing tuberculosis in the UK, TB incidence decreased by $32 \%$ from 2011 to 2015. Explaining this reduction is crucial to informing ongoing TB control efforts.

Methods We stratified TB cases notified in the UK and TB cases averted in the UK through pre-entry screening (PES) between 2011 and 2015 by country of birth and time since arrival. We used population estimates and migration data to establish denominators, and calculated incidence rate ratios (IRRs) between 2011 and 2015. We calculated the contribution of changing migrant population sizes, PES and changes in TB rates to the reduction in TB notifications.

Results TB IRRs fell in all non-EU migrant and UK-born populations between 2011 and $2015(0.61 ; 95 \% \mathrm{Cl}$ 0.59 to 0.64 and $0.78 ; 0.73$ to 0.83 respectively), with the greatest decrease in recent non-EU migrants (0.54; 0.48 to 0.61$) .61 .9 \%$ of the reduction in TB notifications was attributable to decreases in TB rates, $33.4 \%$ to a fall in the number of recent/mid-term non-EU migrants and $11.4 \%$ to PES. A small increase in notifications in EUborn migrants offset the reduction by $6.6 \%$.

Conclusions Large decreases in TB rates in almost all populations accounted for the majority of the reduction in TB notifications, providing evidence of the impact of recent interventions to improve UK TB control. The particularly large decrease in TB rates in recent nonEU migrants provides evidence of the effectiveness of screening interventions that target this population. These findings will inform ongoing improvements to TB control.

\section{INTRODUCTION}

Following major reductions in tuberculosis (TB) during the first eight decades of the 20th century, ${ }^{1}$ TB incidence in the UK increased from the early 1980 s to the mid-2000s, reaching a peak of $14.1 / 100000$ (8919 cases) in $2011,{ }^{2}$ the second highest rate in western Europe. ${ }^{3}$ In the following 4 years, there was a year on year decline in TB incidence, reducing by almost a third (32\%) to 9.6/100 000 (6240 cases) in $2015 .{ }^{2}$ Understanding the causes of this recent reduction is crucial to informing ongoing TB control efforts, and is the key objective of this paper.

Several factors may have contributed to this observed decline. There has been an increasing focus on improving TB control in the UK in recent years, with a diverse range of local initiatives, ${ }^{4-10}$ and most recently a coordinated national approach as set out in the Collaborative TB Strategy for England. ${ }^{11} 12$

\section{Key messages}

What is the key question?

- Why has tuberculosis incidence in the UK fallen by nearly one-third between 2011 and 2015?

What is the bottom line?

- Large decreases in TB rates across almost all population groups explain the majority of the reduction in TB notifications in the UK between 2011 and 2015, with only one-third of the decline due to decreases in the numbers of migrants from high TB burden countries.

Why read on?

- Our study provides strong evidence of recent improvements in UK TB control.

- The nearly $50 \%$ decrease in TB rates in recent non-EU migrants suggests that recent interventions that target this population (preentry screening and the testing and treatment of latent TB infection) have been particularly effective.

In 2011, following a pilot initiated in 2005, the UK rolled out a UK pre-entry TB screening programme, requiring visa applicants from high TB incidence countries $(\geq 40 / 100000)$, who intend to stay in the UK for longer than 6 months to be certified free of pulmonary TB before they can apply for a visa. ${ }^{13}$ In addition, changes in patterns of migration to the UK may have had an impact, as migration can have a considerable influence on TB epidemiology in countries such as the UK, in which a high proportion of cases occur in the non-native born population. ${ }^{14-17}$

In this study, we aim to quantify the relative contribution of changes in migration to the UK, UK pre-entry screening (PES), and changes in TB rates in different population groups to the decline in TB notifications in the UK from 2011 to 2015.

\section{METHODS}

\section{Data sources}

\section{Numerators}

All TB cases notified to the UK enhanced tuberculosis surveillance systems ${ }^{2}$ between 1 January 2011 and 31 December 2015 who had country of birth recorded (96\% of all cases) were included in the study. Cases were stratified into groups according to year of notification, country of birth and, for 
non-EU born TB cases, the time between arrival in the UK and TB notification. The five most common countries of birth (UK, India, Pakistan, Bangladesh and Somalia), accounting for $70 \%$ of all notifications, were analysed individually. Cases from all other countries of birth were grouped into four categories according to the 2010 WHO-estimated TB incidence in their country of origin $^{18}:<40,40-150,151-250$ and $>250$ cases per 100000 . EU and non-EU countries were grouped separately due to differences in the availability of denominator data (see below).

For non-EU born TB cases, time from arrival in the UK to TB notification was used to classify them as recent migrants $(<2$ years since arrival), mid-term migrants (2-5 years since arrival) and long-term migrants (>5 years since arrival). For $6.4 \%$ of records, the year of entry was missing. Missing data were imputed based on country of origin, age and year of notification and subsequently treated as complete data (online supplementary appendix A1).

\section{Population denominators}

To obtain appropriate person-year denominators for observed TB cases, a combination of population estimates and migration data were used.

Resident population estimates were obtained from the Office for National Statistics ${ }^{19}$ and stratified by country of birth and year.

There is no single source of data on migration flows into and out of the UK. ${ }^{20}$ To estimate the annual population size of non-EU migrant groups by country of birth and time since entry, data on the number of visas granted and asylum applications to the UK for each country were obtained from the Home Office. ${ }^{21}$ We included data on visa/asylum numbers from 2007 to 2010 as well as the study period (2011-2015), as this affects the population denominator for recent and mid-term migrants in the study period. The person-year contributions of new migrants that remain in the UK each year was estimated based on distributions of length of stay for different types of visa/asylum applications, treating new migrants as having arrived at the beginning of each year (online supplementary appendix A2). For instance, the number of recent migrants ( $<2$ years since arrival) in the UK in 2011 comprises those migrating to the UK in 2011, plus those that migrated in 2010 who are predicted to have remained in the country in 2011. Similarly, the number of mid-term migrants (2-5 years since arrival) in 2011 comprises those arriving in the years 2007-2009 who are predicted to have remained in the UK until 2011. The annual denominator for long-term migrants ( $>5$ years since arrival) was estimated by subtracting the derived denominator for recent migrants from each country of origin from the Office for National Statistics (ONS) total resident population for each country for each year, under the assumption that all those in the resident population contribute a whole person year.

Denominators for non-UK EU-born populations are based on population estimates alone, as visas are not required for EU migrants, and no other data are available to subdivide them according to time since arrival.

\section{Pre-entry screening}

Data on the number of cases of active TB identified through PES by country were obtained from the Public Health England (PHE) pre-entry TB screening monitoring system. ${ }^{13}$ We assumed that TB cases detected overseas through PES would have become TB cases notified in the UK in that year or the next if, in the absence of PES, they would have successfully been granted a visa and travelled to the UK. We therefore adjusted the number of cases identified through PES by the visa approval rate by country and visa type $\mathrm{e}^{22}$ to calculate the number of cases of TB averted among the recent migrant group.

\section{Statistical analysis}

Notification rates per 100000 for each of the different population groups studied $(\lambda)$ were calculated based on the number of notified TB cases (n) and estimated person-year denominators (N) for each group. Incidence rate ratios (IRR) and 95\% CIs were calculated for the change in $\mathrm{TB}$ incidence rates between 2011 and 2015.

To examine the separate impact of changes in rates of $\mathrm{TB}$ and changes in the sizes of the different population groups on changes in TB notifications between 2011 and 2015, we calculated the predicted number of 2015 TB notifications for each country of birth/time since entry if (1) only the incidence rates had changed and population sizes had stayed the same and (2) only the population sizes had changed and incidence rates had stayed the same (ie, the impact of migration alone).

\section{Calculations}

1. The proportion of TB cases in recent migrants detected by PES, $P$ was calculated as:

$$
P=\frac{\text { Cases identified through PES }}{\text { Cases identified through PES+notifications within } 2 \text { years of entry }}
$$

2. The number of notified cases among recent migrants was defined as:

$$
\text { notifications }=N \cdot \lambda \cdot(1-P)
$$

3. The relative contributions of PES, changing population sizes and $\mathrm{TB}$ rate changes to the overall TB notifications change between 2011 and 2015 was estimated by changing $N, \lambda$ or $P$ from 2011 to 2015 levels in turn, while keeping the other quantities fixed at 2011 levels.

4. We estimated differences in notified cases between 2015 and 2011 attributable to each factor as:

change in population size $/$ migration $=\mathrm{N}_{2015} \cdot \lambda_{2011} \cdot\left(1-\mathrm{P}_{2011}\right)-\mathrm{n}_{2011}$

$$
\begin{aligned}
& \text { change in } \mathrm{TB}=\mathrm{N}_{2011} \cdot \lambda_{2015} \cdot\left(1-\mathrm{P}_{2011}\right)-\mathrm{n}_{2011} \\
& \text { change in } \mathrm{P}=\mathrm{N}_{2011} \cdot \lambda_{2011} \cdot\left(1-\mathrm{P}_{2015}\right)-\mathrm{n}_{2011}
\end{aligned}
$$

where $n_{2011}$ is the number of notified cases in 2011, $N_{\mathrm{i}}$ are population sizes, $\lambda_{\mathrm{I}}$ are TB rates and $P_{\mathrm{i}}$ the proportion of cases identified through PES (recent non-EU migrants only) for respective years.

5. We rescaled individual contributions to match the observed total difference because the sum of predicted differences for each factor may differ from the observed total (all factors in combination).

6. We divided the differences associated with each factor by the total difference in notifications between 2011 and 2015 to give percentage contributions for each factor or group as follows:

$\%$ contribution to overall reduction $=$ predicted group difference/total difference

Results are subject to assumed distributions for length of stay in the UK for different visa/asylum types. If the lengths of stay are longer or shorter in reality, this will alter the population sizes. We therefore conducted a sensitivity analysis to assess the impact of altering the assumed length of stay of migrants with different visa types (online supplementary appendix A6).

To assess the impact of changes in $\mathrm{TB}$ rates in recent and mid-term migrants' countries of origin, we analysed the predicted change in TB rates that would have occurred according 
Table 1 TB cases notified in 2011 and 2015 by country of birth/WHO incidence group and time since arrival in UK, person-year denominators (N) and TB rates per 100000 person-years

\begin{tabular}{|c|c|c|c|c|c|c|c|c|c|c|c|}
\hline \multirow{2}{*}{$\begin{array}{l}\text { Country/ } \\
\text { WHO incidence } \\
\text { group(per } 100000 \\
\text { pop) }\end{array}$} & \multirow[b]{2}{*}{$\begin{array}{l}\text { Time since } \\
\text { arrival }\end{array}$} & \multicolumn{3}{|l|}{2011} & \multicolumn{3}{|l|}{2015} & \multirow[b]{2}{*}{$\begin{array}{l}\text { Diff TB (\% } \\
\text { change) }\end{array}$} & \multicolumn{3}{|l|}{2015 vs 2011} \\
\hline & & TB & $N(1000 s)$ & $\begin{array}{l}\text { Rate per } \\
100000\end{array}$ & TB & $N(1000 s)$ & $\begin{array}{l}\text { Rate per } \\
100000\end{array}$ & & IRR & $P$ value & Ratio N \\
\hline \multirow[t]{3}{*}{$<40$} & $<2$ years & 16 & 183.5 & 8.7 & 14 & 179.7 & 7.8 & $-2(-13 \%)$ & 0.89 (0.44 to 1.83$)$ & 0.758 & 0.98 \\
\hline & 2-5years & 23 & 299.3 & 7.7 & 17 & 222.3 & 7.6 & $-6(-26 \%)$ & $1.00(0.53$ to 1.86$)$ & 0.989 & 0.74 \\
\hline & $>5$ years & 129 & 774.0 & 16.7 & 113 & 898.4 & 12.6 & $-16(-12 \%)$ & 0.75 (0.59 to 0.97$)$ & 0.029 & 1.16 \\
\hline \multirow[t]{3}{*}{$40-150$} & $<2$ years & 89 & 174.1 & 51.1 & 105 & 203.0 & 51.7 & $16(18 \%)$ & 1.01 (0.76 to 1.34$)$ & 0.933 & 1.17 \\
\hline & 2-5years & 145 & 233.3 & 62.1 & 83 & 223.3 & 37.2 & $-62(-43 \%)$ & 0.60 (0.46 to 0.78$)$ & $<0.001$ & 0.96 \\
\hline & $>5$ years & 261 & 450.8 & 57.9 & 190 & 495.9 & 38.3 & $-71(-27 \%)$ & $0.66(0.55$ to 0.80$)$ & $<0.001$ & 1.10 \\
\hline \multirow[t]{3}{*}{$151-250$} & $<2$ years & 109 & 39.4 & 276.8 & 32 & 27.0 & 118.4 & $-77(-71 \%)$ & $0.43(0.29$ to 0.63$)$ & $<0.001$ & 0.69 \\
\hline & 2-5years & 205 & 96.4 & 212.6 & 89 & 60.1 & 148.0 & $-116(-57 \%)$ & $0.70(0.54$ to 0.89$)$ & 0.004 & 0.62 \\
\hline & $>5$ years & 231 & 206.9 & 111.7 & 234 & 333.5 & 70.2 & $3(1 \%)$ & $0.63(0.52$ to 0.75$)$ & $<0.001$ & 1.61 \\
\hline \multirow[t]{3}{*}{$>250$} & $<2$ years & 138 & 71.5 & 193.0 & 91 & 57.0 & 159.8 & $-47(-34 \%)$ & $0.83(0.64$ to 1.08$)$ & 0.162 & 0.80 \\
\hline & $2-5$ years & 201 & 164.6 & 122.1 & 107 & 91.4 & 117.0 & $-94(-47 \%)$ & $0.96(0.76$ to 1.21$)$ & 0.723 & 0.56 \\
\hline & $>5$ years & 621 & 815.7 & 76.1 & 492 & 897.6 & 54.8 & $-129(-21 \%)$ & 0.72 (0.64 to 0.81$)$ & 0.000 & 1.10 \\
\hline \multirow[t]{3}{*}{ India } & $<2$ years & 297 & 134.9 & 220.2 & 112 & 97.0 & 115.5 & $-185(-62 \%)$ & $0.52(0.42$ to 0.65$)$ & $<0.001$ & 0.72 \\
\hline & 2-5years & 633 & 210.9 & 300.2 & 291 & 108.9 & 267.3 & $-342(-54 \%)$ & 0.89 (0.78 to 1.02$)$ & 0.101 & 0.52 \\
\hline & $>5$ years & 937 & 407.2 & 230.1 & 700 & 589.1 & 118.8 & $-237(-25 \%)$ & 0.52 (0.47 to 0.57$)$ & $<0.001$ & 1.45 \\
\hline \multirow[t]{3}{*}{ Pakistan } & $<2$ years & 167 & 60.3 & 277.0 & 43 & 23.1 & 185.9 & $-124(-74 \%)$ & 0.67 (0.48 to 0.94$)$ & 0.020 & 0.38 \\
\hline & 2-5years & 229 & 79.2 & 289.0 & 161 & 65.8 & 244.8 & $-68(-30 \%)$ & 0.85 (0.69 to 1.04$)$ & 0.107 & 0.83 \\
\hline & $>5$ years & 730 & 330.5 & 220.9 & 485 & 414.1 & 117.1 & $-245(-34 \%)$ & $0.53(0.47$ to 0.59$)$ & $<0.001$ & 1.25 \\
\hline \multirow[t]{3}{*}{ Bangladesh } & $<2$ years & 31 & 16.9 & 184.0 & 13 & 7.3 & 176.9 & $-18(-58 \%)$ & $0.96(0.50$ to 1.84$)$ & 0.906 & 0.44 \\
\hline & 2-5years & 90 & 35.7 & 252.2 & 38 & 17.2 & 220.9 & $-52(-58 \%)$ & 0.88 (0.60 to 1.28$)$ & 0.493 & 0.48 \\
\hline & $>5$ years & 170 & 188.5 & 90.2 & 166 & 192.4 & 86.3 & $-4(-2 \%)$ & $0.96(0.77$ to 1.18$)$ & 0.682 & 1.02 \\
\hline \multirow[t]{3}{*}{ Somalia } & $<2$ years & 49 & 3.7 & 1331.6 & 13 & 1.5 & 887.7 & $-36(-73 \%)$ & $0.67(0.36$ to 1.23$)$ & 0.194 & 0.40 \\
\hline & 2-5years & 92 & 15.9 & 578.7 & 39 & 8.6 & 452.5 & $-53(-58 \%)$ & $0.78(0.54$ to 1.14$)$ & 0.198 & 0.54 \\
\hline & $>5$ years & 287 & 88.4 & 324.6 & 133 & 103.9 & 128.0 & $-154(-54 \%)$ & 0.39 (0.32 to 0.48$)$ & $<0.001$ & 1.18 \\
\hline \multirow[t]{4}{*}{ Non-EU total } & $<2$ years & 896 & 684.2 & 131.0 & 423 & 595.6 & 71.0 & $-473(-53 \%)$ & $0.54(0.48$ to 0.61$)$ & $<0.001$ & 0.87 \\
\hline & 2-5years & 1618 & 1135.4 & 142.5 & 825 & 797.6 & 103.4 & $-793(-49 \%)$ & $0.73(0.67$ to 0.79$)$ & $<0.001$ & 0.70 \\
\hline & $>5$ years & 3366 & 3262.0 & 103.2 & 2513 & 3925.0 & 64.0 & $-853(-25 \%)$ & 0.62 (0.59 to 0.65$)$ & $<0.001$ & 1.20 \\
\hline & All & 5880 & 5081.7 & 115.7 & 3761 & 5318.2 & 70.7 & $-2119(-36 \%)$ & 0.61 (0.59 to 0.64$)$ & $<0.001$ & 1.05 \\
\hline $\mathrm{EU}<40$ & All & 209 & 2292.0 & 9.1 & 273 & 2737.0 & 10.0 & $64(31 \%)$ & $1.09(0.91$ to 1.31$)$ & 0.329 & 1.19 \\
\hline EU 40-150 & All & 99 & 290.0 & 34.1 & 196 & 465.0 & 42.2 & $97(98 \%)$ & $1.23(0.97$ to 1.57$)$ & 0.087 & 1.60 \\
\hline EU total & All & 308 & 2582.0 & 11.9 & 469 & 3202.0 & 14.6 & $161(52 \%)$ & 1.23 (1.06 to 1.42$)$ & 0.005 & 1.24 \\
\hline UK & $\mathrm{N} / \mathrm{A}$ & 2221 & 54787.0 & 4.1 & 1751 & 55642.0 & 3.1 & $-470(-21 \%)$ & 0.78 (0.73 to 0.83$)$ & $<0.001$ & 1.02 \\
\hline Total & & 8409 & 62450.7 & 13.5 & 5981 & 64162.2 & 9.3 & $-2428(-29 \%)$ & 0.69 (0.67 to 0.72$)$ & $<0.001$ & 1.03 \\
\hline
\end{tabular}

Comparisons in terms of absolute difference (Diff TB), incidence rate ratios (IRR) and ratios of denominators (N).

to the IRR of WHO-estimated TB incidence by country of birth between 2011 and 2015 and the observed change in TB rates (including both TB notifications in the UK and cases averted by PES) in the same time period.

\section{RESULTS}

Overall changes in TB notifications, 2011-2015

Overall there were 2428 fewer TB notifications in the UK in 2015 compared with 2011 (table 1). The largest reduction in notifications was among non-EU migrants, with 473 fewer notifications in recent migrants, 793 fewer in mid-term migrants and 853 fewer in long-term migrants, together accounting for $87 \%$ of the overall reduction. There was a reduction of 470 notifications in the UK-born population. At the level of individual country of birth, the largest reductions in notifications were among migrants from India, Pakistan, countries with a WHO-estimated TB incidence of $>250 / 10000$ and the UK-born, with a particularly steep fall in notifications between 2013 and 2015 (figure 1).

\section{Changes in population sizes, 2011-2015}

The total numbers of visas granted/asylum applications to the UK decreased between 2007 and 2015, but with peaks around 2009_ 2011 for many countries (figure 2). For all except the $\leq 150$ per $100000 \mathrm{~TB}$ incidence countries, there was a decline in tota visas granted from 2011 to 2015 , but the decrease has varied by visa type in different countries. For the majority of countries of birth, denominators for recent migrants declined between 2011 and 2015 (table 1). For instance, person-year contributions for recent migrants from India and Pakistan fell by $28 \%$ and $62 \%$, 


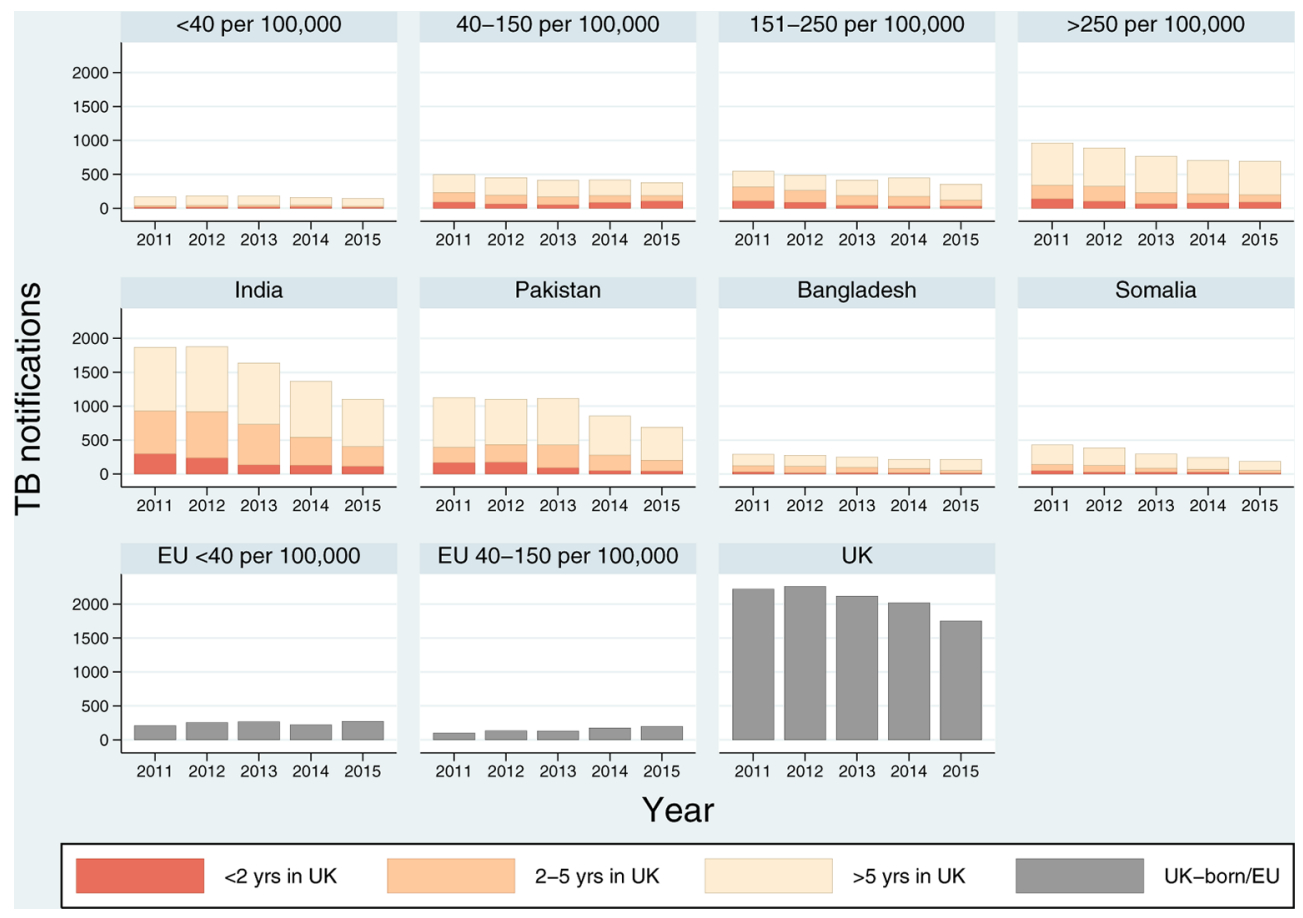

Figure 1 TB cases notified from 2011 to 2015 by country of birth/WHO incidence group and time since arrival in UK.

respectively. Conversely, there was a $24 \%$ increase in personyear contributions for those born in the EU and a $2 \%$ increase for those born in the UK.

\section{Changes in TB notifications, TB incidence and population sizes in migrant populations}

For non-EU migrants, the reductions in notifications between 2011 and 2015 were due to either a significant decrease in TB rates, a reduction in numbers of recent and mid-term migrants or both (table 1). For instance, in recent migrants from India, there was a net reduction of 185 cases between 2011 and 2015 due to a near-halving in TB rates (IRR 0.52) and a $28 \%$ reduction in new migrants.

For all non-EU migrant groups, the size of the long-term migrant population increased over the study period. However, TB notifications have declined for migrants from almost all these countries, leading to overall reductions in TB rates despite the increases in population size. For example, incidence rates declined markedly in long-term migrants (IRR 0.62), leading to a reduction in 853 cases despite a $20 \%$ increase in population size.

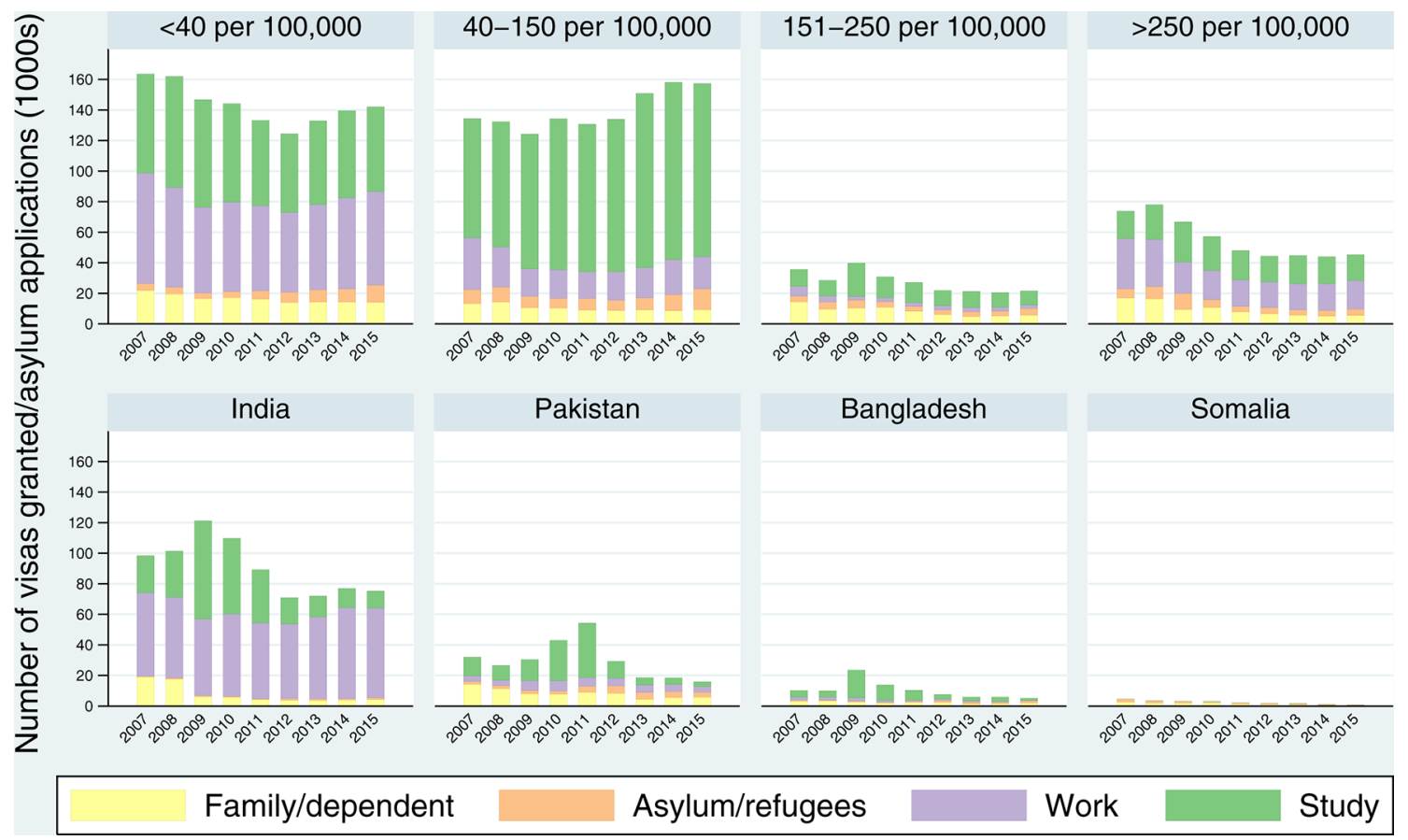

Figure 2 Numbers of visas granted by type (work, study and family/dependent) and asylum applications between 2007 and 2015 by country of birth/WHO incidence group. EU data are not available. 
Table 2 TB notifications, cases identified by PES, population sizes and estimated impact of changes in migration, TB rates and PES on TB notifications between 2011 and 2015

\begin{tabular}{|c|c|c|c|c|c|c|c|c|c|c|}
\hline \multirow[b]{2}{*}{ Population } & \multicolumn{3}{|l|}{2011} & \multicolumn{3}{|l|}{2015} & \multicolumn{4}{|c|}{ Impact on notifications } \\
\hline & Notified TB & PES TB & $\begin{array}{l}\text { Population } \\
(1000 s)\end{array}$ & $\begin{array}{l}\text { Notified } \\
\text { TB }\end{array}$ & PES TB & $\begin{array}{l}\text { Population } \\
(1000 s)\end{array}$ & Migration & TB rates & PES & Total \\
\hline $\begin{array}{l}\text { Recent and mid-term migrants } \\
\text { (non-EU) }\end{array}$ & 2514 & 64 & 1820 & 1248 & 318 & 1393 & $-894(-33.4 \%)$ & $-197(-7.4 \%)$ & $-305(-11.4 \%)$ & $-1266(-52.1 \%)$ \\
\hline Long-term migrants (non-EU) & 3366 & 0 & 3262 & 2513 & 0 & 3925 & 908 & -1357 & 0 & $-853(-35.1 \%)$ \\
\hline EU-born migrants & 308 & 0 & 2582 & 469 & 0 & 3202 & $100(4.6 \%)$ & $43(2.0 \%)$ & $0(0.0 \%)$ & $161(6.6 \%)$ \\
\hline UK-born & 2221 & 0 & 54787 & 1751 & 0 & 55642 & 35 & -497 & 0 & $-470(-19.4 \%)$ \\
\hline
\end{tabular}

Groups are: non-EU migrants (arrived in the UK within 5 years), long-term non-EU migrants (arrived in the UK more than 5 years previously), EU-born migrants and UK-born.

PES, pre-entry screening.

The only exception to the general decrease in TB notifications was among migrants from EU countries, in which there were small, non-significant increases in TB rates and increases in population sizes. However, as EU-migrants contribute only a small number of TB notifications in the UK $(<8 \%$ in 2015), these increases had only a small impact on overall TB numbers (161 more notifications over the study period).

\section{Changes in TB notifications, TB incidence and population size in the UK-born population}

For the UK-born population, a $12 \%$ reduction in TB incidence (IRR 0.78) led to 470 fewer TB notifications, despite a small increase in the overall size of the population (1.6\%).

\section{Cases of active TB identified through the UK pre-entry screening programme}

The number of TB cases identified through the PES programme increased year on year between 2011 and 2015 (online supplementary table A4). In 2015, 382 additional cases of active pulmonary TB were identified and treated outside the UK through PES, compared with 84 in 2011.

\section{Changes in TB incidence in migrant countries of origin}

WHO TB incidence estimates suggest that TB rates have fallen for the majority of countries in the world between 2011 and 2015. The ratio of the predicted number of cases in UK recent

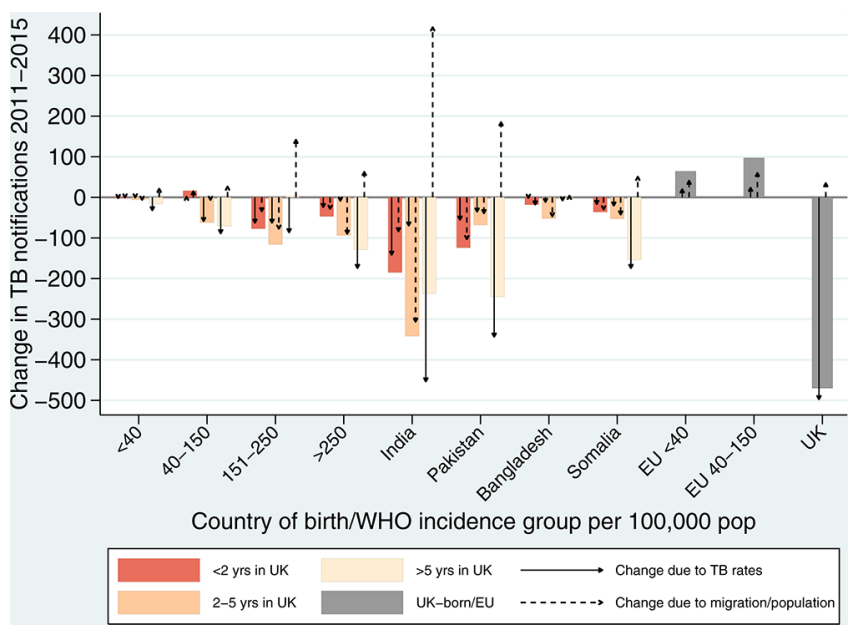

Figure 3 Change in TB notifications from 2011 to 2015 by country of birth/WHO incidence group, observed change (bars) and predicted changes (lines) if only TB rates had changed (but the population size had stayed the same) and if only the size of the population had changed (with no change in TB rates). and mid-term migrants based on WHO TB incidence estimates and the observed number of cases (including both TB notifications in the UK and those averted through PES) varies considerably by country of birth and does not show a clear trend between 2011 and 2015 (online supplementary appendix table $\mathrm{A} 5$ ). Of note, the TB rates observed in those migrating to the UK are quite different to the WHO-estimated incidence in their countries of origin.

\section{Contributions of changing population sizes, pre-entry screening and TB rates to changes in TB notifications, 2011-2015}

On examining the separate impact of changes in rates of TB $(\lambda)$ and changes in population sizes $(\mathrm{N})$ on the number TB notifications between 2011 and 2015 (figure 3), we found that for recent and mid-term non-EU migrants the reduction in population size and the reduction in TB rates had almost equal contribution to the net change in TB notifications. However, for long-term non-EU migrants the factors diverge, and if TB rates in these population groups had not declined, the increase in the population size would have resulted in a marked increase in TB cases.

Our estimates of the relative contribution of changing population sizes, PES and changes in TB rates to the overall reduction in TB notifications in the UK between 2011 and 2015 (table 2 ) suggest that more than half $(54.5 \%)$ of the reduction was due to falls in the TB rate in the UK-born and long-term non-EU migrants, one-third (33.4\%) to changes in non-EU migration to the UK, $11.4 \%$ to cases of TB averted in the UK due to PES and $7.4 \%$ to reductions in the TB rate in recent/ mid-term non-EU migrants. The small increase in the number of EU migrants and rates of TB in this group offset the reduction in notifications by $6.6 \%$.

The sensitivity analysis showed that the overall conclusions of the analysis were not changed by altering the assumed lengths of stay distributions of migrants to be longer or shorter (online supplementary appendix A6). The only notable change to the estimated contributions was a greater estimated impact of the reduction in TB rates in recent/mid-term non-EU migrants if lengths of stay are substantially longer, increasing from $7.4 \%$ to $15.3 \%$. This is primarily due to an increase in the population size in the mid-term migrant group with longer assumed lengths of stay (online supplementary appendix A6).

\section{DISCUSSION}

This is the first published population-level study combining data on TB notifications by country of birth and time since arrival, data on immigration by year and country of origin and data on the yields of cases identified through pre-entry TB screening to 
examine the relative contributions of each of these factors to changes in TB epidemiology.

Our results show that decreases in TB rates in almost all population groups, accompanied by declining numbers of new migrants from high TB burden countries and the impact of PES have led to the marked decreases seen in TB notifications in the UK from 2011 to 2015.

We found that only one-third (33.4\%) of the reduction in UK TB notifications in the 4-year period 2011-2015 can be attributed to the decrease in the number of recent and mid-term migrants from high TB burden countries, with the remainder being independent of changes in the size of migrant population groups.

A number of previous studies have tried to understand the impact of migration on TB epidemiology in low TB incidence countries. ${ }^{1423-25}$ Only two of these studies attempted to quantify the association between immigration and TB incidence, ${ }^{17} 24$ although neither attempted to quantify the impact of migration from different individual countries of birth or the relative contribution of migration compared with other factors in influencing overall TB epidemiology. In addition, although the risk of reactivation of latent TB remains high for many years, ${ }^{16}$ these studies only explored associations between TB and changes in migration in at most the same and the preceding year, and so were unable to explore the impact of migration over a longer time period.

Our finding that two-thirds of the reduction in TB notifications cannot be explained by changes in migration provides strong evidence that interventions to improve UK TB control, both within the UK and through PES, are starting to have an important impact.

Following a successful pilot in 15 countries from 2005 to 2011, from 2012 the UK TB PES programme was rolled out to all long-term ( $>6$ months) visa applicants from high TB-burden countries. ${ }^{13}$ This led to the identification and treatment of 990 cases of active pulmonary TB among visa applicants from 2011 to 2015 . We estimate that 821 of these cases are likely to have had their visas granted and so, if the programme has not been in place, would have entered the UK with untreated TB. We estimate that this intervention led to $11.4 \%$ of the reduction in UK TB cases.

We estimate that more than half $(54.5 \%)$ of the reduction in TB cases in the study period was due to reductions in TB rates within the UK, independent of either changes in migration or the impact of PES. The fact that this observed reduction in TB rates was seen across different population groups, including long-term migrants and the UK-born, suggests that it is likely to reflect the combined impact of a variety of interventions to improve TB services across the UK. These interventions include the establishment and roll-out of Cohort Review, ${ }^{9}$ local projects for the testing and treatment of latent TB infection in new migrants, ${ }^{4-8}$ the establishment of the London Find and Treat service, ${ }^{10}$ the establishment of the national TB MIRU-VNTR Strain Typing Service, ${ }^{26}$ the establishment of TB control boards in some areas, and more recently the publication and roll-out of the Collaborative TB Strategy for England in January 2015. ${ }^{11}$ This strategy built on the local work that went before it, focusing on 10 key areas for action and providing new investment for a national programme of migrant latent TB testing and treatment, ${ }^{27}$ the setting up of TB Control Boards to cover the whole of England and the establishment of a national TB programme office.

While data are not available to explore the relative impacts of each of these different interventions on the reductions in cases, our analyses of changes in TB rates by country of birth and time since arrival in the UK help identify the population groups where improvements have been greatest. The biggest reductions in rates were seen in recent non-EU migrants, in whom rates almost halved (IRR 0.54), but there were also substantial decreases in rates in mid-term and long-term non-EU migrants (IRRs 0.73 and 0.62 , respectively). This suggests that interventions targeted at migrant populations may have been particularly effective.

It is possible that some of the reduction in rates in recent migrants could reflect reduction in TB incidence in their countries of origin. Our analysis of predicted and observed TB rates based on WHO-estimated incidence by country of origin did not show a consistent pattern, which makes it unlikely that changes in incidence in migrants' countries of origin have had an important impact in the UK. Of note, TB rates in migrants to the UK are quite different to the $\mathrm{WHO}$-estimated incidence in their countries of origin, suggesting that migrants are not typical of the overall population in their countries of origin. ${ }^{28}$ Finally, the fact that the observed reduction in TB rates in the UK was seen across population groups, including in the UK-born in whom rates fell by $22 \%$ (IRR 0.78 ), suggests that any influence of changes in incidence rates in migrants' countries of origins is likely to have been small.

A further possible explanation for the reduction in TB rates not directly attributed to changes in migration or PES is the indirect impact of these factors on reducing onward transmission. While this may have contributed to some of the observed reduction in TB rates, previous studies have shown that there is only very limited TB transmission from TB high-prevalence immigrant populations to TB low-prevalence native populations. ${ }^{29} 30$ The fact that TB notifications have fallen in all ethnic groups in the UK, with the second highest reduction observed in the White ethnic group, ${ }^{31}$ therefore suggests that the indirect impact of changes in migration is likely to have made only a small contribution to the overall reduction in notifications.

Our findings are subject to some limitations. First, exact data on the number of migrants entering and leaving the UK each year are not collected, so we used derived denominators based on visa/asylumdata and distributions for subsequent lengths of stay. Visa and asylum applications, although not necessarily representing the true number of people entering the country, provide a good proxy denominator to determine changes in $\mathrm{TB}$ rates over time, assuming that any differences between true numbers entering and visa/asylum applications does not change markedly over time.

Second, our assumptions on length of migrant stay may have an impact on the denominator, particularly for mid-term migrants. However, sensitivity analyses in which lengths of stay were assumed to be longer or shorter did not change our overall conclusions.

Our study has important implications for TB control in the UK. The finding that two-thirds of the reduction in TB is likely due to recent improvements in TB control provides important evidence to support ongoing TB control efforts. The fact that the greatest reduction in TB rates occurred in recent migrants provides evidence of the effectiveness of interventions, such as PES and the testing and treatment of latent TB infection, that particularly target this population. In addition, the fact that the reduction in TB rates has occurred across almost all population groups, including long-term migrants and the UK born, suggests that the wide range of interventions set out in the Collaborative TB Strategy for England are starting to have an important impact. To ensure that these early improvements lead to further reductions in cases will require a sustained effort to build on initial successes and respond to the changing epidemiology of TB in the UK. A particular challenge will be to ensure that 
new migrants to the UK do not face barriers to accessing health services which could create obstacles to latent TB screening and the early diagnosis and treatment of active disease. ${ }^{32}$ In addition, the increasing proportion of TB cases with social risk factors ${ }^{31}$ illustrates the need to further reach out and respond to the needs of vulnerable under-served groups. ${ }^{33}$ In an environment of constrained public finances, maintaining the focus on $\mathrm{TB}$ control will be challenging. However, previous examples of the human, public health and financial costs of allowing successful TB control efforts to unravel ${ }^{34}$ demonstrate the importance of sustaining efforts to eliminate TB as a public health problem. ${ }^{11}$

Contributors HLT, RJH, MCM, JAD, MKL, CNJC and DZ contributed substantially to study conception and design, interpretation of data and revising and editing of the manuscript. In addition, HLT proposed the initial idea for the study and wrote the first draft of the manuscript. MCM and JAD acquired and organised the data and RJH did the statistical analysis. SRA contributed to interpretation of the data and revision and editing of the manuscript.

Funding The authors have not declared a specific grant for this research from any funding agency in the public, commercial or not-for-profit sectors.

Competing interests DZ is head of the Tuberculosis Screening Unit at Public Health England and has shared responsibilities for quality assurance within the UK pre-entry screening programme and leading on the national latent TB screening programme in England. SRA is head of the Public Health England National TB Programme Office. Other authors have no competing interests to declare.

Patient consent Not required. Public Health England has authority under the Health and Social Care Act 2012 to hold and analyse national surveillance data (including tuberculosis pre-entry screening programme data) for public health and research purposes.

Provenance and peer review Not commissioned; externally peer reviewed. (c) Article author(s) (or their employer(s) unless otherwise stated in the text of the article) 2018. All rights reserved. No commercial use is permitted unless otherwise expressly granted.

\section{REFERENCES}

1 Public Health England. TB case notifications by site of disease, England and Wales, 1913-2015. 2016 https://www.gov.uk/government/uploads/system/uploads/ attachment_data/file/554455/TB_case_notifications_1913_to_2015.pdf (accessed 23 Jun 2017)

2 Public Health England. Reports of cases of tuberculosis to enhanced tuberculosis surveillance systems : United Kingdom, 2000 to 2015. Public Heal. Engl. 2016 https:// www.gov.uk/government/uploads/system/uploads/attachment_data/file/555298/TB Official_Statistics_2016_GTW2309.pdf (accessed 23 Jun 2017).

3 European Centre for Disease Control and World Health Organization. Tuberculosis surveillance and monitoring in Europe 2017. 2017 http://ecdc.europa.eu/en/ publications/Publications/ecdc-tuberculosis-surveillance-monitoring-Europe-2017.pdf.

4 Zenner D, Loutet MG, Harris R, et al. Evaluating 17 years of latent tuberculosis infection screening in north-west England: a retrospective cohort study of reactivation. Eur Respir J 2017:50:1602505.

5 Panchal RK, Browne I, Monk P, et al. The effectiveness of primary care based risk stratification for targeted latent tuberculosis infection screening in recent immigrants to the UK: a retrospective cohort study. Thorax 2014;69:354-62.

6 Pareek M, Watson JP, Ormerod LP, et al. Screening of immigrants in the UK for imported latent tuberculosis: a multicentre cohort study and cost-effectiveness analysis. Lancet Infect Dis 2011;11:435-44.

7 Usdin M, Dedicoat M, Gajraj R, et al. Latent tuberculous screening of recent migrants attending language classes: a cohort study and cost analysis. Int J Tuberc Lung Dis 2017;21:175-80.

8 Daly R, Khatib N, Larkins A, et al. Testing for latent tuberculosis infection using interferon gamma release assays in commercial sex workers at an outreach clinic in Birmingham. Int J STD AIDS 2016;27:676-9.

9 Anderson C, White J, Abubakar I, et al. Raising standards in UK TB control: introducing cohort review. Thorax 2014;69:187-9.

10 Jit M, Stagg HR, Aldridge RW, et al. Dedicated outreach service for hard to reach patients with tuberculosis in London: observational study and economic evaluation. BMJ 2011;343:d5376.
11 Public Health England and NHS England. Collaborative tuberculosis strategy for England. 2015 https://www.gov.uk/government/uploads/system/uploads/attachment_ data/file/403231/Collaborative_TB_Strategy_for_England_2015_2020_.pdf (accessed 23 Jun 2017).

12 Abubakar I, Thomas HL, Morgan M, et al. A collaborative strategy to tackle tuberculosis in England. Lancet 2015;385:312-3.

13 Public Health England. UK tuberculosis pre-entry screening report 2015. 2016 https:// www.gov.uk/government/uploads/system/uploads/attachment_data/file/555150/UK_ pre-entry_tuberculosis_screening_2015_GTW230916.pdf (accessed 23 Jun 2017).

14 Gilbert RL, Antoine D, French CE, et al. The impact of immigration on tuberculosis rates in the United Kingdom compared with other European countries. Int I Tuberc Lung Dis 2009;13:645-51.

15 Crofts JP, Gelb D, Andrews N, et al. Investigating tuberculosis trends in England. Public Health 2008;122:1302-10.

16 Pareek M, Greenaway C, Noori T, et al. The impact of migration on tuberculosis epidemiology and control in high-income countries: a review. BMC Med 2016;14:48.

17 Hanway A, Comiskey CM, Tobin K, et al. Relating annual migration from high tuberculosis burden country of origin to changes in foreign-born tuberculosis notification rates in low-medium incidence European countries. Tuberculosis 2016;101:67-74

18 World Health Organisation. WHO TB burden estimates. http://www.who.int/tb/ country/data/download/en/ (accessed 20 Jul 2016).

19 Office for National Statistics. Population of the United Kingdom by Country of Birth and Nationality. http://www.ons.gov.uk/ons/taxonomy/search/index.html? nscl=Population+by+Nationality+and+Country+of+Birth\&nscl-orig=Population by+Nationality+and +Country+of+Birth\&content-type $=$ Dataset\&content-type $=$ Reference+table\&sortDirection=DESCENDING\&sortBy=pubdate (accessed 4 Aug 2016).

20 Hawkins O. Migration Statistics. House of commons briefing paper number SN06077. 2017 http://researchbriefings.files.parliament.uk/documents/SN06077/SN06077.pdf (accessed 2 Jul 2017).

21 Home Office. Entry clearance visas granted by category and country of nationality. Summary. 2016 https://www.gov.uk/government/statistics/immigrationstatistics-january-to-march-2016-data-tables (accessed 14 Jun 2017).

22 Home Office. Entry clearance visa applications and resolution by category and Entry clearance visa applications and resolution by country of nationality. $2017 \mathrm{https}: / /$ www.gov.uk/government/publications/immigration-statistics-january-to-march-2017/ list-of-tables\#visas (accessed 27 Jun 2017).

23 Winston CA, Navin TR, Becerra JE, et al. Unexpected decline in tuberculosis cases coincident with economic recession - United States, 2009. BMC Public Health 2011;11:846.

24 Holland DP, Person AK, Stout JE. Did the 'Great Recession' produce a depression in tuberculosis incidence? Int J Tuberc Lung Dis 2011;15:700-2.

25 Borgdorff MW, van den Hof S, Kremer K, et al. Progress towards tuberculosis elimination: secular trend, immigration and transmission. Eur Respir J 2010;36:339-47.

26 Public Health England. National TB strain typing service: what we do. 2014 https:// www.gov.uk/guidance/national-tb-strain-typing-service-what-we-do (accessed 23 Jun 2017).

27 Public Health England. Latent TB infection (LTBI): testing and treatment. 2015 https:// www.gov.uk/government/publications/latent-tb-infection-ltbi-testing-and-treatment (accessed 8 Jun 2017).

28 International Organization for Migration. World migration report 2000. $2000 \mathrm{http}: / /$ publications.iom.int/system/files/pdf/wmr_2000_edited_0.pdf.

29 Barniol J, Niemann S, Louis VR, et al. Transmission dynamics of pulmonary tuberculosis between autochthonous and immigrant sub-populations. BMC Infect Dis 2009;9:197.

30 Sandgren A, Schepisi MS, Sotgiu G, et al. Tuberculosis transmission between foreign- and native-born populations in the EU/EEA: a systematic review. Eur Respir $J$ 2014:43:1159-71.

31 Public Health England. Tuberculosis in England 2016 Report (presenting data to end of 2015). 2016 www.gov.uk/phe\%7B\%25\%7D0Awww.facebook.com/ PublicHealthEngland (accessed 23 Jun 2017).

32 Potter J. Border control in a healthcare setting is not in the public's best interests. J Public Health 2017;39:219-20.

33 Public Health England, TB Alert NE. Tackling tuberculosis in under-served populations: a resource for tb control boards and their partners. 2017 https://www.gov.uk/ government/uploads/system/uploads/attachment_data/file/592274/Tackling_TB_in_ Under-Served_Populations_-_A_Resource_for_TBCBs_and_partners.pdf (accessed 23 Jun 2017)

34 Brudney K, Dobkin J. Resurgent tuberculosis in New York City. Human immunodeficiency virus, homelessness, and the decline of tuberculosis control programs. Am Rev Respir Dis 1991;144:745-9. 